\title{
An Evolutionary Perspective on Panic Disorder and Agoraphobia
}

\author{
Randolph M. Nesse \\ Department of Psychiatry, University of Michigan
}

Panic, when viewed ethologically, is not pathological in itself; it is rather an adaptation that evolved to facilitate escape in dangerous situations. Patients with panic disorder have panic with normal form, but the attacks occur in the absence of real danger. The agoraphobia syndrome can be understood as a related adaptation that is expected after repeated panic attacks. These hypotheses account for many aspects of panic and agoraphobia that are difficult for proximate theories to explain, and they suggest new research questions and strategies.

KEY WORDS: Evolution; Natural selection; Ethology; Panic attacks; Panic disorder; Anxiety; Agoraphobia.

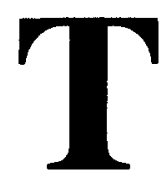
he advances in ethology that have transformed the study of animal behavior are just now being applied to problems of psychopathology. Although most psychiatrists acknowledge the utility of animal models for understanding human behavior, few understand such fundamentals of ethology as the need for evolutionary explanations of behavioral capacities in addition to proximate explanations of the physiological and psychological mechanisms that mediate behavior. The situation is worsened by the tendency of psychiatrists to work mainly in one of three paradigms - analytic, behavioral, or neurophysiological-without recognizing that all three arc limited to questions of proximate causation. Furthermore, recent advances in the biological treatment of mental symptoms have led many to the illogical conclusion that neurophysiological defects underlie most mental disorders. This makes it difficult to consider the possibility that some mental symptoms may, despite their distressing nature, have specific evolved adaptive functions.

The enormous conceptual and experimental progress of the field of animal behavior might long ago have stimulated a new perspective on psychopathology except for three impediments. To begin with, humans are notoriously difficult to study ethologically because their extraordinary learning

Address reprint requests to: Dr. Randolph M. Nesse, Department of Psychiatry, University Hospital, Ann Arbor, MI 48109-0705. 
capacities allow diverse adaptive strategies in a wide variety of habitats. Second, normal behavior patterns of humans have not been extensively investigated in an evolutionary framework. Finally, an additional set of complex issues arises when we try to explain pathology instead of normal behavior. These problems have so far largely precluded the kind of hypothesis testing that is now standard in the field of animal behavior. The speculations that substitute often chagrin animal scientists. We must, however, start somewhere if psychiatry is to share the firm foundation that evolutionary theory provides for the understanding of behavior. A sensible approach is to propose and test hypotheses about specific mental disorders using the large body of data that has already been gathered based on other paradigms.

It is useful to distinguish two categories of medical problems, those that result from defects and those that are normal defenses. Examples of the former include the Babinski sign, which reliably indicates a defect in an upper motor neuron, and paralysis, which indicates some defect in the neuromuscular system. Congestive heart failure also results from defects, although a variety of compensatory mechanisms are also in evidence. Some medical problems are fundamentally different, however, in that they are coordinated response patterns that have evolved to fulfill specific defensive functions. The cough reflex, for example, although usually observed only in the presence of disease or trauma, is an adaptive capacity for clearing foreign material from the pulmonary system. If it is impaired,infection and death are likely. Similar defense mechanisms include the capacities for vomiting, diarrhea, and pain. Although distressing and associated with disease or trauma, they result not from defects, but from the normal operation of adaptive systems.

This distinction is important for two reasons. First, medical interventions that counteract the effects are likely to benefit patients, whereas eliminating defenses is likely to be harmful. The tragic history of thymus gland irradiation illustrates the hazards of eliminating defensive systems that are mistaken for disease. Second, defects and defenses require different kinds of explanation. An analysis of evolutionary origins and functions is required for a defense but is inappropriate for a defect. The immediate cause of a defect is an etiological agent that may disrupt many systems, whereas the immediate cause of a defensive response is a stimulus that acts upon sensors with specific connections to the response mechanism. Although both require physiological explanations, a defense is an integrated series of responses organized to serve a particular function, whereas a defect may involve deficits and compensatory responses in diverse bodily systems.

Do panic attacks result from a defect in a mechanism, or are they a defense? I shall argue that panic is an adaptive defense that facilitates escape from mortal danger; that the abnormality in people with panic disorder is not the occurrence of panic per se, but rather that the attacks occur when there is no real danger; and that agoraphobia can best be understood as a potentially adaptive consequence of repeated panic attacks. This hypothesis 
accounts for many aspects of panic and agoraphobia that cannot be fully explained by hypotheses from the three main proximate paradigms in psychiatry-psychoanalysis, behaviorism, and neurophysiology. I shall briefly review the facts about panic and agoraphobia and then consider the relative ability of each of the four hypotheses to account for these facts.

\section{REVIEW OF PANIC DISORDER AND AGORAPHOBIA}

Panic disorder has long been recognized as a consistent syndrome, although it has been called by many terms, including Dacosta's syndrome, soldier's heart, neuraesthenia, and anxiety hysteria (Wooley 1976). The onset of symptoms is usually in the late twenties or early thirties. The 6-month prevalence of panic disorder in major U.S. cities is approximately 6 per 1000 for men and 10 per 1000 for women. For agoraphobia, the prevalence is approximately 20 per 1000 for men and 50 per 1000 for women (Weissman 1985). To provide an overview, a composite history is presented that incorporates experience with over 100 patients with panic disorder or agoraphobia as well as data from published reports (Tuma and Maser 1985; and other references).

The problem typically begins with a sudden attack of overwhelming anxiety that occurs "from out of the blue" while the person is away from home. A feeling that death is imminent and an overwhelming need to "get out of here" displace all other thoughts. Shortness of breath and pounding of the heart preceed actual movement. Sweating, flushing, dizziness, chest pain, and other physical symptoms are common. The episode last 15-45 minutes and is followed by exhaustion for 24 hours. Days then pass without incident until a second episode suddenly occurs, often in a situation similar to that of the first attack. The person returns home immediately and seeks the company of relatives. Attacks soon become more frequent, and the person spends hours trying to discern the cause in diet, life circumstances, and other factors. Medical evaluation is sought, but findings are not specific, and the patient is told that the symptoms result from "stress" or "hyperventilation." A minor tranquilizer is often prescribed, which reduces anxiety about having attacks, but does not prevent the attacks themselves (Klein 1980). As additional attacks occur, the person avoids more and more situations, finally preferring not to leave home alone. Attacks continue to occur in the home, and the person tries to keep a relative or friend nearby at all times.

After several months the intense brief episodes of anxiety fade, but the person continues to experience intense anxiety in certain situations-being alone or in crowds, being in a wide open space, or being in anyplace where exit is difficult, especially lines, movies, or airplanes (Sheehan et al. 1980; Marks 1970; Marks and Gelder 1966; Arrindell 1980). Finally the patient reads about the disorder in a newspaper article and consults a psychiatrist 
who specializes in treating anxiety disorders. This anxiety specialist explains that psychotherapy is not a reliable treatment (Nemiah 1980; Weiss 1964), but that antidepressant medication will stop the panic attacks (Klein 1980; Sheehan 1982; Zitren et al. 1978, 1980) and that the anticipatory anxieties can be relieved by behavioral exposure therapy (Zitren et al. 1980). After several months of treatment the person is substantially improved but continues to experience apprehension about whether symptoms will recur when the medication is stopped.

\section{THE SYNDROME OF PANIC}

First, let us consider the adequacy of the four hypotheses for explaining the consistent association of the signs, symptoms, and behaviors that comprise the syndrome of panic. Freud suggested that the signs of anxiety-especially excitement, rapid heartbeat and rapid breathing-resemble the state of sexual arousal (Strachey 1959; Fenichel 1945). This explanation fits his original sexual deprivation theory, but it does not explain the chest pain, the wish to flee, feelings of doom, and the cold knot in the abdomen. He later came to believe that the form of panic was determined by birth trauma (Strachey 1959), despite equally serious differences between the two phenomena. Freudian theory thus fails to account for many of the symptoms that characterize the panic syndrome.

Learning theorists usually have not tried to explain the panic syndrome per se. The original panic attack is viewed as an unconditioned response that spreads to new stimuli by stimulus generalization (Marks et al. 1971; Jansson and Lars-Govan 1982; Chambless and Goldstein 1980). The elicitors of the original unconditioned response are however, rarely evident. Even if they were, the syndrome of panic symptoms, with its remarkable consistency across patients with widely varying histories, would remain unexplained.

Neurochemical theories seeking to delineate the brain mechanisms that control and mediate anxiety will continue to extend our understanding of the physiological mediators of panic (Uhde et al. 1985). Regardless of how adequate such proximate theories become, however, it will also be necessary to consider the evolutionary origins of the brain mechanisms that give humans the capacity for panic (Hinde 1982; Mayr 1982). Can the panic syndrome be accounted for by "sympathetic arousal," for example? The fact that behavior patterns and subjective symptoms cannot be elicited by hormone administration casts doubt on such a proposition. Moreover, even a complete description of the neuroendocrinology underlying panic would not encompass the adaptive emotional and behavioral responses that occur in many species during emergencies. The emphasis on functional significance inherent in Cannon's (1926) phrase "fight or flight" seems to have been forgotten by those who believe that a proximate explanation would alone be sufficient. Tricyclic antidepressants and monoamine oxidase inhibitors 
are very effecctive at stopping panic attacks, and this effect is unrelated to the amount of depression the patient is experiencing (Sheehan et al. 1980; Zitren et al. 1983). The known effects of these medications on amine neurotransmitters, and the involvement of the sympathetic nervous system in panic (Nesse et al. 1984; Stokes 1985) suggest that they act by influencing these systems. This conclusion may well be correct, but it does not imply that an organic defect is necessarily present. If panic is indeed a complex defense mechanism, then we should not be surprised that panic attacks can be blocked by disrupting the system at a number of different points.

Susceptibility to panic disorder is genetically transmitted (Torgersen 1983). Although this fact may seem to imply that an organic defect is involved, it is equally compatible with the view that panic is an adaptive defense. Like any other trait, the threshold for the panic response should be normally distributed in a population. Data from rhesus monkeys suggest substantial genetically determined differences in anxiety levels (Suomi et al. 1981). People with panic disorder may be at one end of such a distribution. If this is the case, then the current confident search for a specific defect could prove fruitless. My guess is, however, that some cases of panic disorder will turn out to result from defects in the mechanism that regulates the expression of panic. This is based on the fact that panic attacks often come "out of the blue" in perfectly safe surroundings. Moreover, they usually occur with substantial frequency for a period of several months and then go away (Raskin et al. 1982). This seems unlikely to represent simply an inherited threshold difference. Whether an inherited defect turns out to be important or not, the research seeking it will help us to understand the genetic, developmental, and environmental factors that regulate the threshold for and expression of panic.

Many aspects of panic disorder that are difficult for other theories to explain make sense if the syndrome is viewed as an adaptation that evolved to facilitate flight from life-threatening danger. The sudden increase in the rate and strength of cardiac contractions sends extra blood to the muscles, while the gut feels empty and the skin blanches and becomes cold as blood is shunted elsewhere. Rapid and deep breathing increases blood oxygen content. Cooling sweat is secreted, muscles tighten and tremble, and the endocrine system prepares for catabolism (Nesse et al. 1984; Mason 1968). Intense mental activity is focused on planning escape. When the overwhelming urge to flee is translated into action, all effort is concentrated on escape. The direction of flight is towards home and trusted kin, a behavior pattern typical of animals that rely on homes and kin for protection. These aspects of the panic syndrome are exactly what one would expect in a behavior pattern that facilitates escape. Of the 12 symptoms that define a panic attack according to the third edition of the American Psychiatric Association Diagnostic and Statistical Manual (DSM-III) (American Psychiatric Association 1980), 8 either directly aid flight or are secondary manifestations of responses that aid flight. By excluding "life-threatening situations" from 
consideration, the DSM-III tacitly acknowledges that this response is expected in the face of serious danger.

Donald Klein's closely related view of panic and agoraphobia (1981) is also based on ethological considerations, but he emphasizes the similarities of panic to childhood separation anxiety and its evolutionary function of maintaining proximity of toddler and parent, as proposed by Bowlby (1973). Klein's theory views panic as a regression phenomenon, in contrast to the view presented here that emphasizes its normal adaptive function in adults. Several facts suggest that panic in adults is different from separation anxiety in children. First, the behaviors exhibited are phenomenologically different. Crying and withdrawal, or searching for the parent, predominate in separation anxiety, whereas flight and the physiological preparation for it predominate in panic. Second, panic disorder usually begins in the late twenties and is not continuous with the peak of separation anxiety in childhood. Third, panic is recognized as a normal response to danger, not to separation. Despite these differences, panic and separation anxiety may be intimately related. Normal development may transform one capacity into the other, and developmental interference may cause a person to exhibit a combination of the two behavior patterns in circumstances that vaguely threaten separation or physical danger.

In summary, the various components of the syndrome of panic and their reliable association cannot be fully explained by analytic, behavioral, or neurophysiological theories. A combination of these theories may eventually give us an adequate proximate explanation of the mechanisms of panic. If panic is an evolved adaptation, however, then a separate evolutionary explanation is also required. The hypothesis that the capacity for panic serves the function of facilitating escape from mortal danger is consistent with the available facts about the panic syndrome and implies that panic does not necessarily involve an organic defect.

\section{THE AGORAPHOBIA SYNDROME}

Although described in the DSM-III as a separate syndrome, agoraphobia is almost always a complication of repeated panic attacks. In $95 \%$ of the agoraphobics evaluated in our anxiety clinic, agoraphobia developed after repeated "spontaneous" panic attacks. Agoraphobia is another remarkably consistent syndrome. Patients share the same fears of wide-open spaces, closed-in places, being alone, being in crowds, and being far from home (Marks 1969, 1970; Sheehan et al. 1980; Matthew et al. 1981; Arrindell 1980). How can the nature and consistency of these fears be explained?

Dynamic theory interprets the street in this syndrome as a symbol for sexual opportunities and interprets being alone as an opportunity for forbidden masturbation (Strachey 1959). Convincing support for the generality of these interpretations is not available. Even if it were, they still would not 
explain other aspects of the agoraphobia syndrome, such as the consistent fear of lines, travel by public transportation, and being far away from home. Learning theory suggests that each panic attack conditions additional stimuli, and that fears therefore generalize until the patient is afraid to leave home (Chambless and Goldstein 1981). This appears to be true, but it leaves unexplained both the fact that home-bound patients do not develop fear of the home and the consistent constellation of fears in different people. After association with a single panic attack, a previously neutral situation may gain the capacity to elicit anxiety. Learning theory attributes this to classical conditioning. This one-trial learning is, however, quite different from the learning of a salivation response after repeated pairings of a conditioned stimulus with food. Learning is itself a product of natural selection and is constrained by the evolutionary history of each species (Seligman and Hager 1972; Hamilton 1975). Where one-trial learning is adaptive-for instance, food aversion learned after a single episode of gastrointestinal illness-it may well be preserved in the species (Bernstein 1978). If danger were encountered at a particular spot, individuals who were ready to flee upon coming again to the same spot would have a selective advantage. Agoraphobics do not develop fear of the specific object of attention at the moment of panic, but of the general area in which the attack occurred. This tendency may represent an example of "prepared learning" (Seligman 1971). Moreover, certain situations, because of their association with increased risk of danger during primate evolution, may have acquired the capacity to decrease the threshold for panic. An open landscape without trees offers no safe refuge; a closed-in space increases the risk of being trapped. Being alone and being among strangers far from home are situations that also increase risk for humans. The need for proximity to kin, repeatedly induced by panic attacks, may explain the dependency of people with agoraphobia. Attack by carnivores must have been a serious risk, but strange humans could have posed a even greater risk. These factors may help to explain the relative frequency of panic and agoraphobia in women. Women might benefit more than men from a low panic threshold and a tendency to avoid distant or isolated places because they are relatively less able to defend themselves, because of the difficulty of flight with children, because they represent a potential reproductive resource for another group, and because food-gathering typically requires shorter excursions than does hunting. The efficacy of behavioral exposure therapy is also consistent with an evolutionary view. of the function of agoraphobic fears. Many simple phobias are probably prepared fears, and their repeated elicitation without bad effects decreases the fear. Behavior theory leads to effective treatment but offers only a partial etiologic explanation.

In summary, people with a prepared tendency to be apprehensive in certain situations have a survival advantage, and repeated experiences of danger are an ideal cue for the avoidance of these situations. This hypothesis explains the constellation of fears that comprise the agoraphobia syndrome, 
the distinctive conditions that relieve these fears, and the fact that agoraphobia is a common complication of repeated panic attacks. The other theories cannot. Whether agoraphobic tendencies are latent in all of us, or are atavistic remnants possessed only by a few, is a question for further study.

\section{IMPLICATIONS}

A theory that considers the adaptive functions of panic attacks can explain many aspects of panic and agoraphobia that other theories cannot. An evolutionary explanation for panic and agoraphobia is not an alternative to proximate theories; it is rather the necessary other half of a complete explanation of any biological phenomenon. Therefore, support for the above proximate explanations does not undermine the above evolutionary explanation. Opponents of the evolutionary explanation proposed must argue either that the phenomenon has not been directly shaped by natural selection and has no adaptive function or that the proposed function is incorrect. An answer to the question, "What evolutionary forces have shaped the capacity for panic?" leaves open separate questions about learning, dynamic conflicts, the specific neurochemical mechanisms that mediate the capacity, and whether or not the mechanism is defective in people with panic disorder. Because other psychiatric conditions also likely have adaptive aspects, an evolutionary perspective on panic may provide a structure for a biopsychosocial model of panic disorder that can serve as a paradigm for improved understanding of other psychiatric disorders.

How can the proposed theories about the evolutionary functions of panic and agoraphobia be tested? Even if they are consistent with the large body of accumulated fact and can explain evidence that other theories cannot, our confidence in them must be limited until they successfully predict new findings. This task is difficult because panic is a rare phenomenon that cannot be ethically and reliably elicited in a laboratory setting. Nonetheless, a variety of predictions are possible, based on three requirements for an adequate evolutionary explanation: (1) that the capacities should be genetically influenced, (2) that the elicitors, form, and effects of the behaviors should be consistent with the proposed function, and (3) that individuals who lack the capacity should be, under natural conditions, at a fitness disadvantage directly related to the proposed function.

1. If the capacities for panic and agoraphobia are genetically based, then syndromes similar to agoraphobia and panic disorder should be observed in most humans in a variety of cultures. Although some evidence on the nature of anxiety in other cultures is available, specific studies of panic and agoraphobia are needed. Other primate species should show similar responses, modified to fit their environment. Stress reactions have been studied extensively in primates, but field researchers may not have looked for this specific pattern, as distinct from fear. 
2. Specific precipitants of panic and the fears of agoraphobics should be predicted by the theory. Any situation that indicates mortal threat should reliably elicit panic attacks in normal people. Such situations might be difficult to study in the laboratory, but data on the precipitants and nature of panic in normal people would be valuable evidence.

3. Panic threshold should be normally distributed in the population. If panic patients form a second peak in the distribution, then this would support the search for an organic defect. If they are simply on the tail of the distribution, then a defect is less likely. Unfortunately, I can see no easy way to measure panic threshold. Perhaps nonpanic indicators of panic threshold could be used.

4. The proposed function of panic attacks should predict new details about the attacks. For instance, many animals freeze for a moment when danger is first sensed, presumably to decrease chances of detection by a predator. Observation of freezing behavior in a rabbit prompted me to ask panic patients if they experienced momentary freezing or paralysis at the onset of an attack. Of 15 patients, 5 said that this was a prominent symptom that no one had ever asked about before.

5. The consequences of panic should be adaptive in dangerous situations. Individuals deprived of this response should be at a fitness disadvantage. If there were a way to pharmacologically deprive wild primates of the capacity for panic without confounding side effects, the theory predicts that they would be subject to increased predation.

6. Medications that block panic attacks by blocking the mechanism of panic expression should also block normal panic. Other medications may simply reset the panic threshold closer to normal.

7. Agoraphobia should be precipitated only after repeated panic attacks. In a consecutive series of cases reported elsewhere, only 1 out of 53 patients with panic attacks and agoraphobia had the onset of agoraphobia first, with panic attacks usually occurring for several months before the onset of the agoraphobia.

Finally, an ethological perspective has benefits in the clinic. Most patients with panic attacks arrive worried that they are crazy, weak, medically ill, or all three. I have found, with several dozen patients, that a simple explanation of the adaptive function of panic in normal people is readily grasped and greatly appreciated. Patients who understand this do not ask, like others, "So, Doctor, is it physical or psychological?" This understanding of their symptoms allows them to take responsibility for cooperating with treatment without having to feel responsible for the illness itself. An ethological approach organizes the symptoms in a comprehensible way and offers a perspective that can promote a strong therapeutic alliance for the integrated biological, psychological, and social treatment of panic disorder and agoraphobia. 
REFERENCES

Arrindell, W.A. Dimensional structure and psychopathology correlates of the fear survey schedule (FSIII) in a phobic population: A factorial definition of agoraphobia. Behavior Research and Therapy 18: 229-242, 1980.

Bernstein, I.L. Learned taste aversions is children receiving chemotherapy. Science 200: 13021303,1978 .

Bowlby, J. Separation. New York: Basic, 1973.

Cannon, W.B. The emergency function of the adrenal medulla in pain and the major emotions. American Journal of Physiology 33: 356-372, 1926.

Chambless, D.L., and Goldstein, A.J. Clinical treatment of agoraphobia. In Phobia: Psychological and Pharmacological Treatment, M.R. Mavissakalian and D.H. Barlow (Eds.). New York: Guilford, 1980.

Crowe, R.R., Noyes, R. Jr., Pauls, D.L., and Slyman, D.J. A family study of panic disorder. Archives of General Psychiatry 40: 1065-1069, 1983.

Diagnostic and Statistical Manual of Mental Disorders, 3rd ed. Washington D.C.: American Psychiatric Association Press, 1980.

Fenichel, O. The Psychoanalytic Theory of Neurosis, New York: Norton, 1945.

Hamilton, W.D. Innate Social Aptitudes of Man: An approach from evolutionary genetics. In Biosocial Anthropology, R. Fox (Ed.). New York: Wiley, 1975.

Hinde, R.A. Ethology. New York: Oxford University Press, 1982.

Jansson, L., and Lars-Govan, O. Behavioral treatments for agoraphobia: An evaluative review. Clinical Psychology Review 2: 311-336, 1982.

Klein, D.F. Anxicty reconceptualized In Anxiety: New Research and Changing Concepts, D.F. Klein and J. Rabkin (Eds.). New York: Raven, 1981.

Marks, I.M. Fears and Phobias. New York: Academic, 1969.

- Agoraphobic syndrome (phobic anxiety state). Archives of General Psychiatry 23: 538$553,1970$.

and Gelder, M.G. Different ages of onset in varieties of phobia. American Journal of Psychiatry 123: 218-221, 1966.

- Boulougouris, J., and Marset, P. Flooding versus desensitization in the treatment of phobic patients. A crossover study. British Journal of Psychiatry 119: 353-375, 1971.

Mason, J.W. Overall hormonal balance as a key to endocrine functions. Psychosomatic Medicine 30: 791-808, 1968.

Matthew, A.M., Gelder, M.G., and Johnson, D.W. Agoraphobia: Nature and Treatment. New York: Guilford, 1981.

Mayr, E. The Growth of Biological Thought: Diversity, Evolution and Inheritance. Cambridge, MA: MIT Press, 1982.

Nemiah, J.C. Phobic disorder. In Comprehensive Textbook of Psychiatry, 3rd ed. H.I. Kaplan, A.M. Freedman, and Sadock, B.J. (Eds.). Baltimore, Williams \& Wilkins, 1980.

Nesse, R.M., Curtis, G.C., Thyer, B.A., McCann, D., and Huber-Smith, M.J. Adrenergic function in panic anxiety patients. Archives of General Psychiatry 41: 771-776, 1984.

- Curtis, G.C., Thyer, B.A., McCann, D., and Huber-Smith, M.J. Endocrine and cardiovascular responses during phobic anxiety. Psychosomatic Medicine 47: 320-332, 1985.

Raskin, M., Peeke, H.V.S., Dickman, W., and Pinkster, H. Panic and generalized anxiety disorders: Developmental antecedents and precipitants. Archives of General Psychiatry 39: 687-689, 1982.

Seligman, M.E.P. Phobias and preparedness. Behavior Therapy 2: 307-320, 1971.

- , and Hager, J.L. (Eds.). Biological Boundaries of Learning. New York: Appleton-Century-Crofts, 1972.

Sheehan, D.V. Panic Attacks and phobias. New England Journal of Medicine 307: 156-158, 1982.

_- Ballenger, J., and Jacobsen, G. Treatment of endogenous anxiety with phobic, hysterical and hypochondriacal symptoms. Archives of General Psychiatry 37: 51-59, 1980.

Stokes, P.E. The neuroendocrinology of anxiety. In Anxiety and the Anxiety Disorders. A.H. Tuma, and J.D. Maser (Eds.). Hillsdale, NJ: Erlbaum, 1985. 
Strachey, J. Editor's introduction. In S. Freud Inhibitions, Sympioms and Anxiety. New York, Norton, 1959, pp. 3-12.

Suomi, S.S., Kramer, G.W., Baysinger, C.M., and DeLizio, R.D. Inherited and experiential factors associated with individual differences in anxious behavior displayed by rhesus monkeys. In Anxiety: New Research and Changing Concepts, D.F. Klein and J. Rabkin (Eds.). New York: Raven, 1981.

Tuma, A.H., and Maser, J.D. Anxiety and the Anxiety Disorders. Hillsdale, NJ: Erlbaum, 1985.

Torgersen, S. Genetic factors in anxiety disorders. Archives of General Psychiatry 40: 1085, 1983.

Uhde, T.W., Roy-Byrne, P.P., Vittone, B.J., Boulenger, J.P., and Post, R.M. Phenomenology and Neurobiology of Panic Disorder. In A.H. Tuma and J.D. Maser (Eds.) Anxiety and the Anxiety Disorders. Hillsdale, NJ: Erlbaum, 1985.

Weissman, M.M. The Epidemiology of anxiety disorders: rates, risks, and familial patterns. In Anxiety and the Anxiety Disorders. A.H. Tuma and J.D. Maser (Eds.). Hillsdale, NJ: Erlbaum, 1985.

Wooley, C.F. Where are the diseases of yesteryear? Circulation 53: 745-751, 1976.

Zitren, C.M., Klein, D.F., and Woerner, M.G. Behavior Therapy, supportive psychotherapy, imipramine and phobias. Archives of General Psychiatry 35: 307-316, 1978.

- Klein, D.F., and Woerner, M.G. Treatment of agoraphobia with group exposure in vivo and imipramine. Archives of General Psychiatry 37: 63-72, 1980.

- Klein, D.F., Woerner, M.G., and Ross, D.C. Treatment of phobias. I. Comparison of imipramine hydrochloride and placebo. Archives of General Psychiatry 40: 125-138, 1983. 